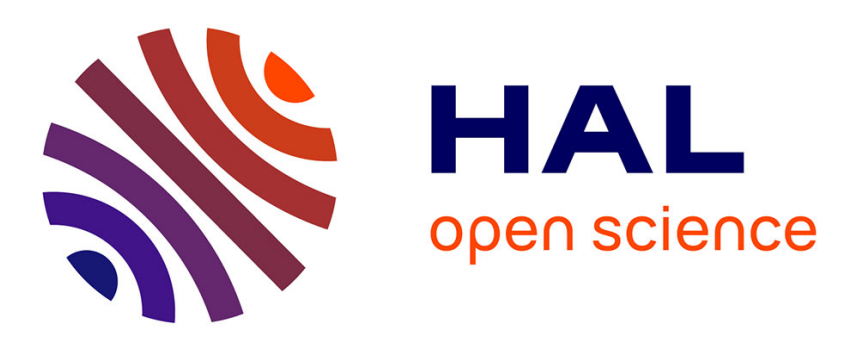

\title{
Mechanical and Dielectric Energy Loss Related to Viscous Motion and Freezing of Domain Walls
}

\author{
Y. Wang, Yue Huang, H. Shen, Zhen Zhang
}

\section{To cite this version:}

Y. Wang, Yue Huang, H. Shen, Zhen Zhang. Mechanical and Dielectric Energy Loss Related to Viscous Motion and Freezing of Domain Walls. Journal de Physique IV Proceedings, 1996, 06 (C8), pp.C8-505-C8-514. 10.1051/jp4:19968110 . jpa-00254540

\section{HAL Id: jpa-00254540 https://hal.science/jpa-00254540}

Submitted on 1 Jan 1996

HAL is a multi-disciplinary open access archive for the deposit and dissemination of scientific research documents, whether they are published or not. The documents may come from teaching and research institutions in France or abroad, or from public or private research centers.
L'archive ouverte pluridisciplinaire HAL, est destinée au dépôt et à la diffusion de documents scientifiques de niveau recherche, publiés ou non, émanant des établissements d'enseignement et de recherche français ou étrangers, des laboratoires publics ou privés. 


\title{
Mechanical and Dielectric Energy Loss Related to Viscous Motion and Freezing of Domain Walls
}

\author{
Y.N. Wang, Y.N. Huang, H.M. Shen and Z.F. Zhang \\ National Laboratory of Solid Microstructures, Nanjing University, Nanjing 210093, China
}

\begin{abstract}
Three dielectric loss $(D)$ and/or three mechanical loss $\left(Q^{-1}\right)$ peaks $\left(P_{1}, P_{2}, P_{3}\right)$ and corresponding susceptibilities for ferroelectric KDP and TGS, and ferroelastic LNPP crystal and $\mathrm{Cu}-\mathrm{Al}-\mathrm{Zn}-\mathrm{Ni}$ alloy have been investigated in the $\mathrm{kHz}$ range. $P_{1}$ and $P_{2}$ almost overlap for first order phase transitions. $P_{1}$, a very narrow peak, is attributed to the dynamic domains due to fluctuations near $T_{C} . P_{2}$ is recognized to be related to domain walls (DWs). The formulas of $Q^{-1}$ and $D$ caused by the viscous motion of DWs are derived, being fairly coincident with the experimental data of $P_{2}$. The viscous coefficient, pinning force constant of $D W$ and the spontaneous shear strain have been calculated for $\mathrm{Cu}-\mathrm{Al}-\mathrm{Zn}-\mathrm{Ni}$. The susceptibility, $\varepsilon^{\prime}$ or $\Delta \mathrm{J} / \mathrm{J}$, always shows a high plateau below $T_{C}$ and drops down rapidly nearly consistent with the low temperature side of $P_{3}$ peak for poly-domain TGS, KDP and $\mathrm{Cu}-\mathrm{Al}-\mathrm{Zn}-\mathrm{Ni}$. $\mathrm{P}_{3}$ is thought to originate from the freezing of $\mathrm{DWs}$ of high density due to a collective pinning of randomly distributed defects, similar to the pinned-vortex glass model suggested for hîgh $\mathbf{T}_{\mathrm{C}}$ superconductors.
\end{abstract}

\section{INTRODUCTION}

Often three energy loss peaks below $T_{c}$ appear in internal friction or dielectric measurements for ferroelastic and ferroelectric materials. Peak $P_{1}$ just at $T_{c}$ is very narrow and difficult to measure, and for 1 st order phase transitions, $P_{1}$ and $P_{2}$ always overlap. So, in many cases only two separated peaks may be observed. The dielectric loss (D) or mechanical dissipation $\left(Q^{-1}\right)$ peak $P_{2}$ just below Tc is commonly attributed to domain walls [1-8]. The mobility of DWs plays an important role in ferroelectric memory, the shape memory effect, and even in high damping capacity. If a correlation between $\mathrm{D}$ (or $\mathrm{Q}^{-1}$ ) and the amount as well as mobility of domain wall can be found, the memory effect can be studied by using the dynamic method. Snead and Welch [8] have proposed a theory of $Q^{-1}$ in A15 alloys on the basis of the movement of DWs. The result is in accordance with the experimental data at the high temperature side of the peak in pure A15 alloy, but not with other results. Firstly we need to find out experimentally the relation between the loss $\mathrm{D}$ (or $\mathrm{Q}^{-1}$ ) and the $\mathrm{DWs}$. $\mathrm{La}_{1-\mathrm{x}} \mathrm{Nd}_{\mathrm{x}} \mathrm{P}_{5} \mathrm{O}_{14}$ (LNPP) undergoes an $\mathrm{mmmF} 2 / \mathrm{m}$ 2nd order ferroelastic transition at $141^{\circ} \mathrm{C}$. Thus, in a LNPP single. crystal, phase interfaces are absent, only twin DWs occur in the ferroic phase, and there is a simple domain structure (all walls are parallel planes often crossing the whole sample) making the abovementioned investigation possible. From studies on LNPP, we obtained a relation between $\mathbf{Q}^{-1}$ and the amount of DWs [9]. To investigate the mobility of DWs, the frequency dependence of the energy loss peak $\mathrm{P}_{\mathbf{2}}$ for KDP, TGS, Cu-Al-Zn-Ni and $\mathrm{Mn}-\mathrm{Cu}$ has been investigated by both experimental and theoretical analysis [10-11], from which the viscous coefficient and the pinning force constant of DWs can be acquired[12]. These parameters are important for studies on problems in memory devices, such as fatigue life or stabilization and switching rate.

A third peak $P_{3}$ often occurs at a lower temperature than of $P_{1}$ and $P_{2}$, which is also related to DWs. The dielectric loss peak $P_{3}$ in KDP showing freezing effect of DWs has been studied in detail[13-23]. The dielectric constant ( $\left.\varepsilon^{\prime}\right)$ parallel to the ferroelectric axis is anomalously high as compared to the value predicted by the phenomenological Landau theory [13-18]. On cooling, $\varepsilon$ ' shows a plateau-like 
temperature dependence below $T_{C}$, and then at a lower temperature $T_{f}$ abruptly decreases down to its phenomenological value, forming a 'kink'. The peak $P_{3}$ covers the temperature range of the 'kink'. The anomalously large dielectric constant in the temperature interval $T_{f}<T<T_{c}$ (the "plateau" region) is believed to be due to the motion of the domain walls. The abrupt decrease of the dielectric constant is then attributed to the freezing of domain walls. At least three models to describe this freezing effect have been proposed: by those (1) Bornarel [14,18,22], (2) Fedosov and Sidorkin [15] and (3) Kuramoto and Nakamura $[16,19,21,23]$. These models can explain some experimental results, but some questions are still open. The Vogel-Fucher relation $\tau=\tau_{0} \mathrm{e}^{\mathrm{U} /\left(\mathrm{T}-\mathrm{T}_{1}\right)}$ [24], the criterion for relaxation due to the freezing process, has been measured only in the high frequency range $\left(10^{6} \mathrm{~Hz}\right)$ [16]. The low frequency range $\left(10^{3} \mathrm{~Hz}\right)$ reveals a static hysteresis character[17], although $\varepsilon^{\prime}$ goes down rapidly at $T_{\mathrm{f}}$. In this paper, we give a detailed results about the frequency dependence of $P_{3}$ in the kilo-Hertz range, and propose a new model-collective pinning of DWs.

As we know, there always appears a large peak at a lower temperature than of the phase transition peak $\left(\mathrm{P}_{1}+\mathrm{P}_{2}\right)$ in shape memory alloys. Only the peak in $\mathrm{Mn}-\mathrm{Cu}$ alloy [25] has been confirmed to be attributed to the twin walls, but those in NiTi [26] and $\mathrm{Cu}-\mathrm{Zn}-\mathrm{Al}[27]$ are usually suggested to be caused by dislocations together with point defects. In view of the large peak height and peak width, we speculated it likely originate from the DWs interacting with point defects. In this paper, the primary results on $\mathrm{P}_{3}$ with the possible freezing effect for $\mathrm{Cu}-\mathrm{Al}-\mathrm{Zn}-\mathrm{Ni}$ will be reported.

\section{EXPERIMENTS AND SPECIMENS}

The internal friction and elastic constant in the low kilo-Hertz range were measured by a two-node clamped-reed vibration technique with electrostatic drive and detection device, and measurement in the $50-150 \mathrm{kHz}$ range was carried out on a Marx three-component resonator. The dielectric loss ( $\varepsilon$ ") and the dielectric constant $\left(\varepsilon^{\prime}\right)$ were measured on a GR1615-A Capacitance bridge with sample size about $10 \times 10 \times 1 \mathrm{~mm}^{3}$. A torsion pendenlum was used for low frequency measurements. The samples reported in this paper are listed in the table:

\begin{tabular}{|c|c|c|c|c|}
\hline & $\begin{array}{c}\text { chemical formula or } \\
\text { composition }\end{array}$ & $\begin{array}{c}\text { type of phase } \\
\text { transition }\end{array}$ & $\begin{array}{c}\text { order of phase } \\
\text { transition }\end{array}$ & $\begin{array}{c}\text { temperature of phase } \\
\text { transition }\end{array}$ \\
\hline $\mathrm{LNPP}$ & $\mathrm{La}_{1-\mathrm{x}} \mathrm{Nd}_{\mathrm{x}} \mathrm{P}_{5} \mathrm{O}_{14}$ & ferroelastic & 2nd order & $141^{\circ} \mathrm{C}$ \\
\hline $\mathrm{TGS}$ & $\mathrm{NH}_{2}\left(\mathrm{H}_{2} \mathrm{COOH}\right)_{3} \cdot \mathrm{H}_{2} \mathrm{SO}_{4}$ & ferroelectric & 2nd order & $322 \mathrm{~K}$ \\
\hline $\mathrm{LATGS}$ & $\alpha-$ alanine $\mathrm{TGS}$ & ferroelectric & 2nd order & $323 \mathrm{~K}$ \\
\hline $\mathrm{KDP}$ & $\mathrm{KH}_{2} \mathrm{PO}_{4}$ & ferroelectric & weak 1st order & $122 \mathrm{~K}$ \\
\hline $\mathrm{Cu}-\mathrm{Al}-\mathrm{Zn}-\mathrm{Ni}$ & $\begin{array}{c}\mathrm{Cu}-28.76 \mathrm{at} \% \mathrm{Al}- \\
4.76 \mathrm{at} \% \mathrm{Zn}-2.33 \mathrm{at} \% \mathrm{Ni}\end{array}$ & $\begin{array}{c}\text { thermoelastic } \\
\text { martensitic }\end{array}$ & 1 st order & $\begin{array}{c}\mathrm{A}_{\mathrm{s}}=60^{\circ} \mathrm{C} \\
\mathrm{A}_{\mathrm{f}}=95^{\circ} \mathrm{C}\end{array}$ \\
\hline $\mathrm{Cu}-\mathrm{Zn}-\mathrm{Al}-\mathrm{Mn}$ & $\mathrm{Cu}-22.5 \mathrm{at} \% \mathrm{Zn}-9.3 \mathrm{at} \% \mathrm{Al}-$ & $\begin{array}{c}\text { thermoelastic } \\
\text { martensitic }\end{array}$ & 1 st order & $\begin{array}{c}\mathrm{A}_{\mathrm{s}}=50^{\circ} \mathrm{C} \\
\mathrm{A}_{\mathrm{f}}=76^{\circ} \mathrm{C}\end{array}$ \\
\hline $\mathrm{Mn}-\mathrm{Cu}$ & $\mathrm{Mn}-20 \mathrm{wt} \% \mathrm{Cu}$ & $\begin{array}{c}\text { thermoelastic } \\
\text { martensitic }\end{array}$ & 1 st order & \\
\hline
\end{tabular}

\section{EXPERIMENTAL RESULTS AND ANALYSIS}

\subsection{Energy Loss Spectrum for LNPP, KDP, TGS, LATGS, Cu-Zn-Al-Ni and Cu-Al-Zn-Ni}

\subsection{1 $\mathrm{La}_{1-x} \mathrm{Nd}_{x} \mathrm{P}_{5} \mathrm{O}_{14}$ Crystal}




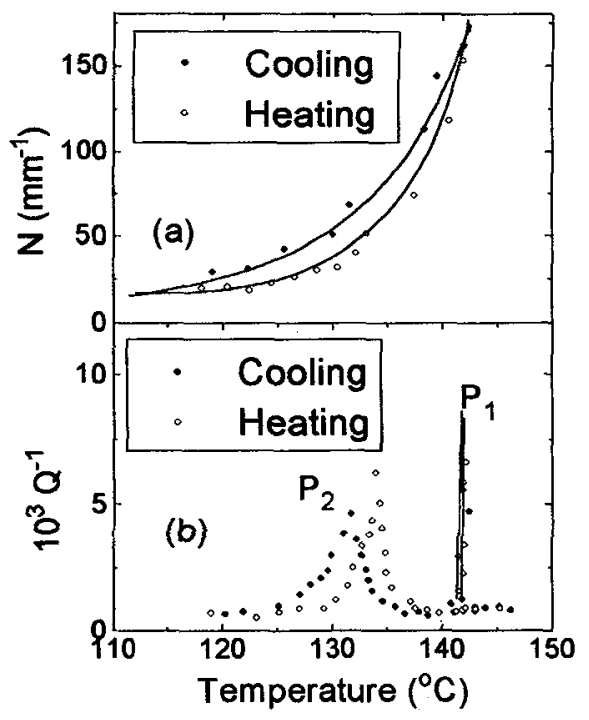

Fig. 1. Density of DWs $\mathrm{N}$ and $\mathrm{Q}^{-1}$ vs $\mathrm{T}$ for LNPP

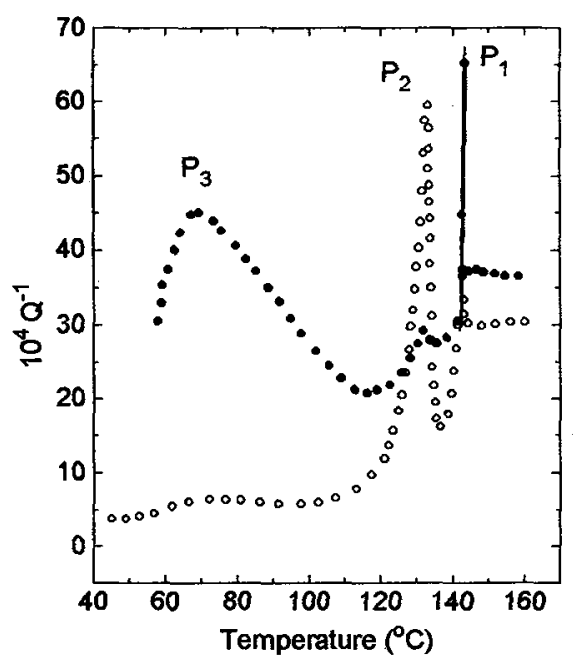

Fig. 2. $Q^{-1}$ vs $\mathrm{T}$ before $(\bullet)$ and after $(0)$ removing the 'frozen domains in LNPP'
The LNPP samples were cut along the c-axis from a single crystal of composition $x=0.9$. Measurements in the $50-150 \mathrm{kHz}$ range were carried out in a special furnace in which domains of a sample can be observed in situ with a polarization microscope during $\mathrm{Q}^{-1}$ measurements [9]. Two $Q^{-1}$ peaks $(f \approx 50 \mathrm{kHz})$ at $\sim 134$ ${ }^{\circ} \mathrm{C}\left(\mathrm{P}_{2}\right)$ and $141^{\circ} \mathrm{C}\left(\mathrm{P}_{1}\right)$, are shown in Fig. 1(b) [9]. $\mathrm{X}$ ray analysis and measurement of the elastic constant $\mathrm{C}_{55}$ [9] show that the peak temperature of $P_{1}$ is located just at $\mathrm{T}_{\mathrm{C}}\left(141^{\circ} \mathrm{C}\right)$, whereas no structural change was detected at the peak temperature of $P_{2}$. In situ observation of DWs during the $Q^{-1}$ measurement show that the density of DWs, $N$, increases with $T$, nearly proportional to $\left(1-\mathrm{T} / \mathrm{T}_{\mathrm{C}}\right)^{-1}$ [Fig. 1(a)], so-called domain coarsening (or thinning). The peak temperature of $P_{2}$ corresponds to the temperature where $\mathrm{N}$ begins to increase rapidly $(\mathrm{N}=(50 \pm 10) \mathrm{mm})$. Both $\mathrm{P}_{2}$ and the $\mathrm{N}-\mathrm{T}$ curve show remarkable thermal hysteresis. The thermal hysteresis and the abrupt formation of a new domain, just like a martensite plate, indicate the coarsening (or thining) of domains has the character of first-order phase transitions. This is also confirmed by the heat capacity results [11].

The peak $P_{1}$ that appears at $141^{\circ} \mathrm{C}$ has no thermal hysteresis within the resolution of $0,1 \mathrm{~K}$. This means that it must originate from a second-order phase transition. However, among the conventional theories of energy dissipation of second-order phase transitions, such as the Landau-Khalatnikov theory of relaxation of the order parameter and the theory of fluctuation dissipation [9], it is generally predicted that $Q^{-1}$ is too small to be detected in the kilohertz range. So, the peak $P_{1}$ at low frequency has been attributed to the stress-induced preferred orientation of domains of the dynamic new phase $[1,9]$ due to fluctuation near $\mathrm{T}_{\mathrm{C}}$.

Another peak $P_{3}$ occurs at temperatures below that of $P_{1}$ and $P_{2}$ (Fig. 2). If a small stress is applied to a LNPP sample at a higher temperature, the coarsening is frustrated, i.e. a large number of domains are frozen down to a lower temperature[9]. As a result, $P_{2}$ is suppressed, while $P_{3}$ becomes much larger. So, $P_{3}$ is still considered to be induced by domain walls, but with a different mechanism from $P_{2}$. At higher temperatures, the domain walls cannot be pinned by point defects, so the dissipation of $\mathrm{P}_{2}$ may comes from the interaction between DWs and the lattice. By contrast, $P_{3}$, at a lower temperature, which is sensitive to defects, may be ascribed to the thermal assistant motion of pinned DWs. 


\subsubsection{KDP and TGS Crystal}

The dielectric constant $\left(\varepsilon^{\prime}\right)$ and dielectric loss $\left(\varepsilon^{\prime \prime}\right)$ as functions of temperature for KDP, DKDP and TGS crystals were measured at various frequencies. Fig. 3 shows the results for TGS and LATGS, with three loss peaks $P_{1}, P_{2}$ and $P_{3}$. $P_{1}$ which occurs just at $T_{C}$, often failed to appear in the measurements due to its extreme narrowness. Similarly to that in LNPP, it is attributed to the dynamic domains of the new phase due to fluctuation near Tc. $P_{2}$ and $P_{3}$ in TGS were recognized to be related to DWs, as they disappear in monodomain LATGS, but the mechanisms are still open. The peaks $P_{2}$ and $P_{3}$ in KDP and DKDP, similar to that in Fig. 3 are also confirmed to originate from domain walls (Figures omitted here).

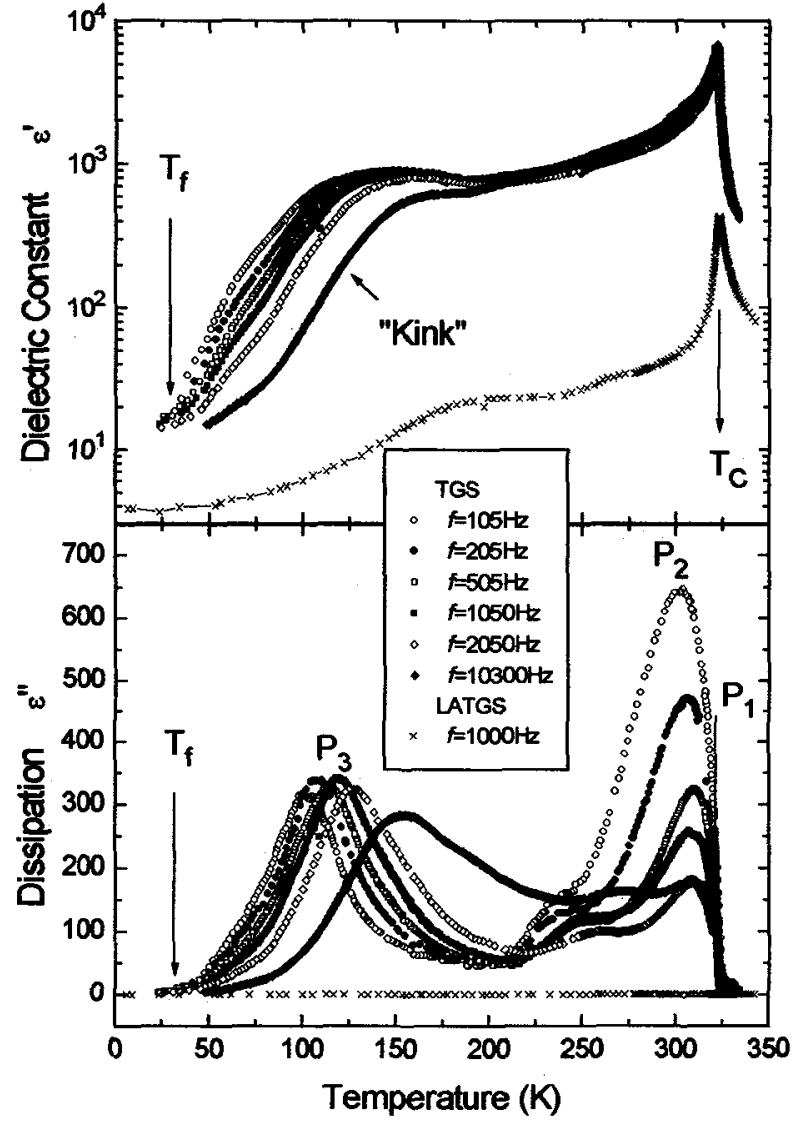

Fig. 3. Dielectric measurements for TGS: (a) $\varepsilon$ 'vs $T$ at various frequencies; (b) $\varepsilon$ " vs $T$ at various frequencies
The dielectric constant $\varepsilon^{\prime}$ vs $T$ curves for KDP, DKDP and TGS show the same characteristics: a high plateau in a rather large temperature range, rapid drop at a certain lower temperature $\left(\mathrm{T}_{\mathbf{f}}\right)$, forming a kink, below which $\varepsilon^{\prime}$ remains unchanged. The kink region corresponds closely to the low temperature side of the peak $P_{3}$. It is evident that the peak $P_{3}$ is associated with a freezing effect.

Because KDP crystal is both ferroelectric and ferroelastic, the internal friction must have the same characteristics as the dielectric measurements. $\mathrm{Q}^{-1}$ for $\mathrm{KDP}$, measured at $2 \mathrm{kHz}$, does exibit three peaks similar to the dielectric peaks [10].

\subsubsection{Cu-Zn-Al-Mn and Cu-Al-Zn-Ni Alloy}

Thermal-elastic martensitic transformation in alloys such as $\mathrm{Cu}-\mathrm{Zn}, \mathrm{Cu}-\mathrm{Al}, \mathrm{Ni}$ $\mathrm{Ti}, \mathrm{Mn}-\mathrm{Cu}$ and etc. possesses almost all the characteristics of a ferroelastic transition except that the thermal hysteresis is generally larger than that in oxide crystals.

Fig. 4 shows the internal friction spectrum for a $\mathrm{Cu}-\mathrm{Zn}-\mathrm{Al}-\mathrm{Mn}$ alloy. The sample was heated at $850^{\circ} \mathrm{C}$ for 10 min., followed by quenching in oil at $120^{\circ} \mathrm{C}$ for $40 \mathrm{~min}$., then colling down. A sharp peak $\left(\mathrm{P}_{1}, \mathrm{P}_{2}\right)$ is due to martensitic transformation, and a broad peak $P_{3}$ appears at a lower temperature.

As mentioned in the introduction, a peak similar to $P_{3}$ appears in many shape memory alloys, which needs confirmation that it originates from domains. To obtain various domain structures, different thermo-mechanical treatments for $\mathrm{Cu}-\mathrm{Al}-\mathrm{Zn}-\mathrm{Ni}$ sample were used. Firstly, the sample was heated at $1123 \mathrm{~K}$ for $15 \mathrm{~min}$, followed by quenching into oil at $393 \mathrm{~K}$ for $45 \mathrm{~min}$, then by cooling to room temperature in air. The internal frictions after such treatment is shown by curve $I$ in Fig. 5 , revealing peak $P_{3}$. Afterward, we stretched the sample by $3 \%$ at room temperature. Then it was heated first at $873 \mathrm{~K}$ for $1.5 \mathrm{hr}$, second at $1123 \mathrm{~K}$ for $1.5 \mathrm{hr}$, followed by the same cooling process as that for curve $\mathrm{I}$. 
$\mathrm{Q}^{-1}$ after the 2 nd treatment is shown by curve II (Fig. 5). Compared to curve I, the peak height decreases much. Metallographic observation showed that the domain size is much smaller (therefore more domain walls) for the first treatment of the sample than for of the second. It may be considered this peak is also associated with DWs.

These results indicate that there generally exist two relaxation processes connected with domain walls: $P_{2}$ occurs near the phase transition temperature $T_{C}$ and drops rapidly with temperature closely up to $T_{C}$; $P_{3}$ appears near the freezing temperature $T_{f}$, dropping to zero when the temperature goes to $T_{f}$. It is reasonable to speculate that $P_{2}$ is caused by an interaction of DWs with the lattice and $P_{3}$ originates from the interaction of DW with defects. However, the detailed mechanisms need further study as presented below.

\section{2 $\mathbf{P}_{2}$ Peak and Viscous Motion of Domain Wall}

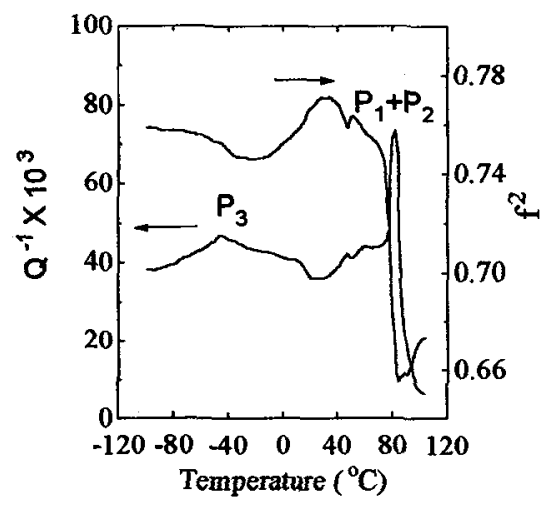

Fig. 4. $Q^{-1}$ and $f^{2}$ vs $T$ for Cu-Zn-Al-Mn after treated as described in text. $f=0.76 \mathrm{~Hz}$

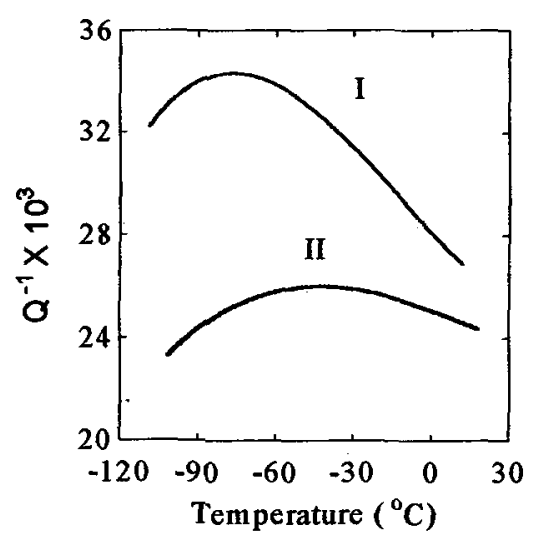

Fig. $5 Q^{-1}$ vs $T$ (peak $P_{3}$ ) for Cu-Al-Zn$\mathrm{Ni}:$ I. thin domain; II. coarse domain. $\mathbf{f}=1 \mathrm{~Hz}$
3.2.1 KDP and TGS: To get more information about the mechanism of the $P_{2}$ peaks, the dependence of both $Q^{-1}$ and the dielectric loss on frequency was surveyed further. It was discovered that the high temperature sides of the peaks are almost independent of frequency, but the low temperature sides are frequency dependent and the positions of the peaks move to higher temperature as the frequency increases (Fig. 6,7), but the relaxation time does not obey the Arrhenius relation [10]. The similar figures for TGS were published in [10]. This behavior is quite different from that of a thermally activated peak. The peaks may be considered to be related to a complicated viscous movement of DWs.

\subsection{2 $\mathrm{Cu}-\mathrm{Al}-\mathrm{Zn}-\mathrm{Ni}$ and $\mathrm{Mn}-\mathrm{Cu}$ Alloy:}

The Cu-28.76at\%Al-4.76at\%Zn-2.33at\%Ni sample was kept at $830^{\circ} \mathrm{C}$ for 10 minutes, followed by air quenching to room temperature. The characteristic temperatures on heating are $A_{8}=60{ }^{\circ} \mathrm{C}$ and $A_{f}=95{ }^{\circ} \mathrm{C}$. An internal friction peak appears at $78^{\circ} \mathrm{C}$, which is found to be independent of the measuring frequency $(0.7 \mathrm{kHz}$ and $1.98 \mathrm{kHz})[12]$, similar to the results of the low frequency internal friction associated with the martensitic transformation, revealing a mechanism of static hysteresis type. Moreover, the results from 50 to $150 \mathrm{kHz}$ [Fig. 8] show an unsymmetrical internal friction peak at the same temperature as that measured near $1 \mathrm{kHz}$. Fig. 9 shows the results for $\mathrm{Q}^{-1}$ and $\triangle \mathrm{E} / \mathrm{E}$ for a $\mathrm{Mn}-\mathrm{Cu}$ alloy which was heated at $950^{\circ} \mathrm{C}$ for $20 \mathrm{~min}$ and quenching in water. The peak temperature $\left(T_{P}\right)$ in Fig. 8 and Fig. 9 increases with measuring frequency and the relationship between $\ln f$ and $T_{P}{ }^{-1}$ disobeys the Arrhenius relationship, which indicates that the internal friction peak is neither a static hysteresis loss nor a thermally activated Debye relaxation, very similar to those of the internal friction peak $P_{2}$ in KDP and TGS crystals. 


\subsection{Theoretical Analysis}

As mentioned above, $P_{2}$ is thought to be caused by the interaction between $\mathrm{DWs}$ and the lattice. There are two mechanisms: one is due to static friction, just as the Peierls force on the dislocation; the other is dynamic friction due to the viscous motion of DWs in lattice. Here we consider the latter case only, because the loss is frequency dependent.

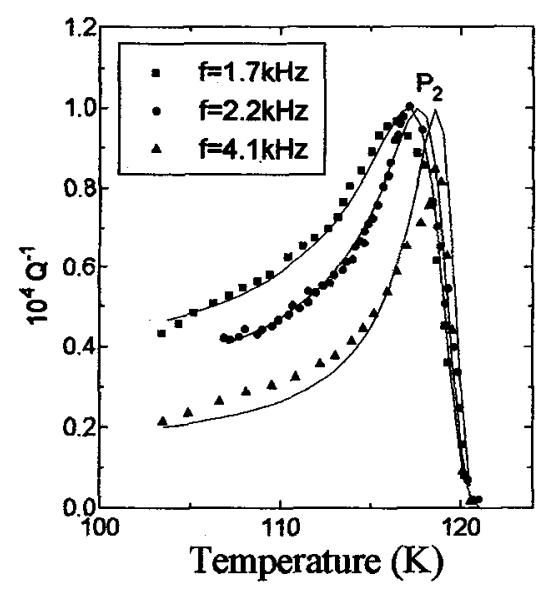

Fig. 6. $Q^{-1}$ vs $T$ for various $f$ in $K D P$.

Theor. $(-)$ with $\mathrm{A} / \mathrm{k}=5.4 \times 10^{-2} \mathrm{~s} . \mathrm{B}=9.5 \mathrm{~K}$.

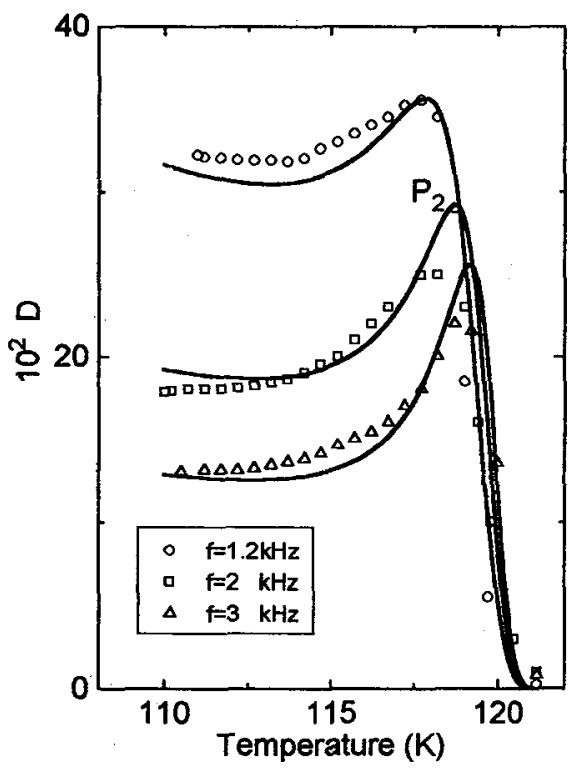

Fig. 7. $D$ vs $T$ for various $f$ in $\mathrm{KDP}$. Theor. ( $\left(\right.$ ) with $\mathrm{A} / \mathrm{k}=1.3 \times 10^{-2} \mathrm{~s}, \mathrm{~B}=9.5 \mathrm{~K}$.
There are five forces acting on domain walls [10]: (1) the configuration force $\mathrm{F}_{\mathrm{C}}$ by the external field, (2) the interaction force between the nearest-neighbor DWs $F_{1},(3)$ the viscous force $-\Gamma \dot{x}$ as DWs move in the lattice, where $\Gamma$ is the viscosity coefficient, (4) the recovering force $-\mathrm{k}_{0} \mathrm{X}$ due to the pinning defects, where $\mathrm{k}_{0}$ is the force constant, and (5) the Peierls force which, although existing, is relatively small and can be neglected here.

Letting $M$ be the effective mass per unit area of DWs and $x$ be the displacement of the wall under the applied stress, the equation of motion of a DW is

$$
M \ddot{x}+\Gamma \dot{x}+k_{0} x-F_{I}=F_{C}
$$

It is easily deduced from the energy change due to the displacement of the interfaces under the applied force that [10]

$$
\begin{aligned}
& \mathrm{F}_{\mathrm{C}}=2 \varepsilon_{i j}^{(s)} \sigma_{\mathrm{ij}} \\
& \mathrm{F}_{\mathrm{I}}=-2 \mathrm{C}_{\mathrm{ijj}} \mathrm{N}\left[\varepsilon_{i j}^{(s)}\right]^{2} \mathrm{x}=-\mathrm{k}^{\prime} \mathrm{x} \\
& \varepsilon_{i j}^{(d)}=\varepsilon_{i j}^{(s)} \mathrm{x} / \mathrm{d}
\end{aligned}
$$

where $\varepsilon_{i j}^{(s)}$ is the spontaneous shear strain, $\mathrm{C}_{\mathrm{ijij}}$ is the corresponding shear modulus, $\sigma_{i j}$ is the effective shear stress which can drive the DWs to move, $\varepsilon_{i j}^{(d)}$ is the shear strain caused by the displacement $\mathrm{x}$ of $\mathrm{DW}$ under an applied stress, $\mathbf{N}$ is the average number of parallel interfaces per unit perpendicular distance. So, $\mathrm{N}=\mathrm{d}^{-1}$ where $\mathrm{d}$ is the distance between the nearest-neighbour interfaces. $\mathrm{Q}^{-1}$ is

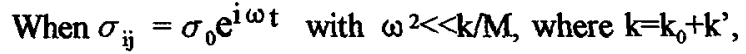

$$
\mathrm{Q}^{-1}=\frac{2 \mathrm{~N}\left[\varepsilon_{i j}^{(s)}\right]^{2}}{\mathrm{Jk}} \frac{\omega \tau}{1+\omega^{2} \tau^{2}}
$$

where $\tau=\Gamma / k$ is the relaxation time, and $J$ is the compliance.

The expression for $\Gamma$ obtained by Combs and Yip[28] with constants $A$ and $B$ is 


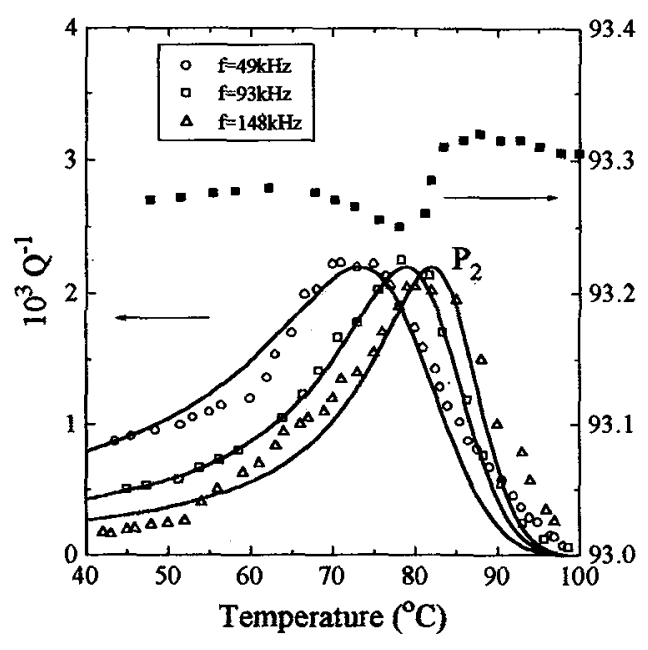

Fig. $8 \mathrm{Q}^{-1}$ vs $\mathrm{T}$ for $\mathrm{Cu}-\mathrm{Al}-\mathrm{Zn}-\mathrm{Ni}$ at different $f$. Curves drawn for $\mathrm{A} / \mathrm{k}=7.0 \times 10^{-4} \mathrm{sec} . \mathrm{B}=130 \mathrm{~K}$.

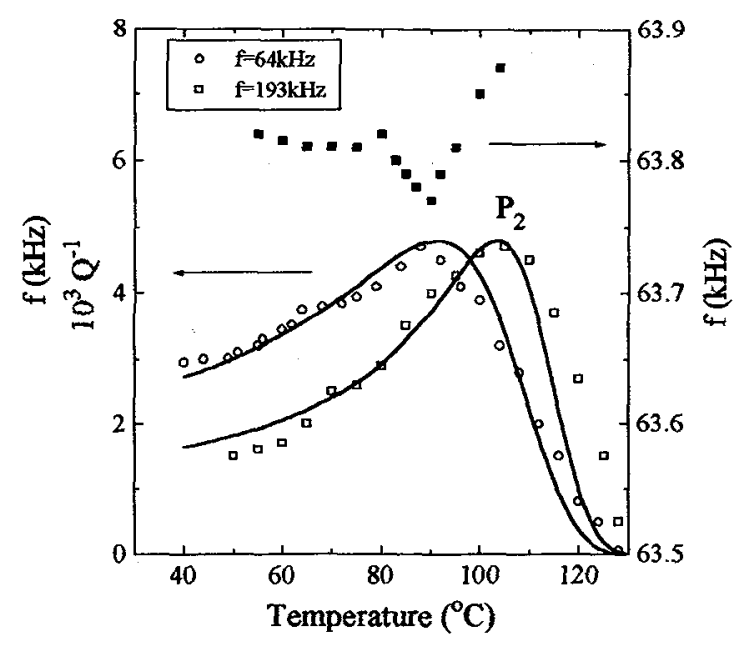

Fig.9. $\mathrm{Q}^{-1}$ vs $\mathrm{T}$ for $\mathrm{Mn}-\mathrm{Cu}$ at different $f$. - Curves for $\mathrm{A} / \mathrm{k}=1.5 \times 10^{-4} \mathrm{sec}$., $\mathrm{B}=110 \mathrm{~K}$.

$$
\Gamma=A e^{-B /\left(T_{c}-T\right)}
$$

Similarly, the dielectric loss $D\left(=\varepsilon " / \varepsilon^{\prime}\right)$ can be deduced to be

$$
\mathrm{D}=\frac{2 \mathrm{NP}_{\mathrm{s}}^{2} / \mathrm{k}}{\left[\chi_{m m}\left(\chi_{m m}+2 \mathrm{NP}_{s}^{2} / \mathrm{k}\right)\right]^{1 / 2}} \frac{\omega \tau}{1+\omega^{2} \tau^{2}}
$$

where $P_{S}$ is the spontaneous polarization, $\chi_{\mathrm{mm}}$ is the susceptibility of monodomain crystal along the direction of $P_{s}$.

For a second order, or a weak first order, phase transition, $\mathrm{N} \approx \mathrm{N}_{\mathrm{o}} /\left(\mathrm{T}_{\mathrm{C}-\mathrm{T}}\right), \mathrm{P}_{\mathrm{s}}^{2}\left[\right.$ or $\left.\left(\varepsilon_{i j}^{(s)}\right)^{2}\right] \propto\left(\mathrm{T}_{\mathrm{C}-\mathrm{T}}\right)$. So, $\mathrm{NP}_{\mathrm{s}}{ }^{2}$ and $\mathrm{N}\left[\varepsilon_{i j}^{(s)}\right]^{2}$ are nearly independent of $\mathrm{T}$. If we can measure $\mathrm{N}$ and $\mathrm{P}_{\mathrm{s}}$ (or $\varepsilon_{i j}^{(s)}$ ) at a temperature within the peak, we can get $\mathrm{k}$ from (5) or (7). By the computer simulation of $\mathrm{Q}^{-1}$ or $\mathrm{D}$ curves, $A / \mathrm{k}$ and $\mathrm{B}$ are easily obtained, thus $\Gamma$ can be calculated. Theoretical curve shown in Figures 6,7, 8 and 9 are fairly close to the experimental data. $\mathrm{A} / \mathrm{k}$ and $\mathrm{B}$ for $\mathrm{KDP}, \mathrm{Mn}-\mathrm{Cu}$ and $\mathrm{Cu}-\mathrm{Al}-\mathrm{Zn}-\mathrm{Ni}$ are given in the captions. The value of $B$ for KDP obtained from the $Q^{-1}$ data is the same as from the dielectric loss curve, and the theoretical curves are in good agreement with the data measured at various frequencies, indicating that the mechanism of viscous motion of DW is reasonable. The high temperature side of peak $P_{2}$ drops rapidly to zero at $T_{C}$, which is easily explained. The spontaneous strain or polarization tends to zero as $\mathrm{T} \rightarrow \mathrm{T}_{\mathrm{C}}$, so the difference between the domain wall and the domain interior becomes small, thus the scattering by phonons to DWs tends to 0 , then the viscous coefficient, $\Gamma \rightarrow 0$ and the relaxation time $\tau=(\Gamma / k) \rightarrow 0$ rapidly [see formula (6)], as does $Q^{-1}$ (or $D$ ).

For $\mathrm{Mn}-\mathrm{Cu}$ and $\mathrm{Cu}-\mathrm{Al}-\mathrm{Zn}-\mathrm{Ni}$ the agreement between theory and experiment is fairly good on the low temperature side, but not on the high temperature side. The reason may be that the change of $N$ on high temperature side is not so simple as for KDP due to the 1st order phase transition. However, the starting points are nearly at the same temperature $A_{f}$ for different frequencies, quite different from the thermal activated relaxation peak, for which the starting point should shift in parallel with the peak temperature. The other important point is that the $\mathrm{Q}^{-1}$ peak of $\mathrm{Mn}-\mathrm{Cu}$, as well as $\mathrm{Cu}-\mathrm{Al}-\mathrm{Ni}$ alloys, near 
$1 \mathrm{kHz}$ (see Ref. [12], Fig. 1) is much narrower than at $\sim 100 \mathrm{kHz}$. That means the variation of $\mathrm{N}$ is concentrated in temperature range near the peak temperature $T_{P}$. The broadening of the low temperature side of peak $P_{2}$ at $\sim 100 \mathrm{kHz}$ is due to the viscous motion of DWs. So, we can use the data in this region to calculate $\Gamma$ and $\mathrm{k}$. As an example, $\Gamma$ and $\mathrm{k}$ for $\mathrm{Cu}-\mathrm{Al}-\mathrm{Zn}-\mathrm{Ni}$ have been calculated as follows [12]. The average density of DWs $\mathrm{N}$ is counted to be $1.2 \times 10^{5} / \mathrm{m}$. The elastic modulus is calculated to be $1.5 \times 10^{5} \mathrm{MPa}$ from the resonant frequency. The spontaneous strain was obtained by using the results of $\mathrm{x}$-ray diffraction in $\mathrm{Cu}-\mathrm{Al}-\mathrm{Zn}-\mathrm{Ni}$. The structure of the orthorhombic $\mathrm{r}_{1}$ martensite is $\mathrm{Cu}_{3} \mathrm{Ti}$ type with lattice parameters, $\mathrm{a}=0.4382 \mathrm{~nm}, \mathrm{~b}=0.5356 \mathrm{~nm}, \mathrm{c}=0.4222 \mathrm{~nm}$ and the structure of the parent phase is $\mathrm{DO}_{3}$ type with lattice parameter $\mathrm{a}_{0}=0.5836 \mathrm{~nm}$, which is similar to the results obtained by $K$. Otsuka et al [29]. The martensitic transformation belongs to the $\mathrm{m} 3 \mathrm{mFmmm}$ (ss) ferroelastic phase transition, that means the principal axes in the $r_{1}^{\prime}$ martensitic phase are parallel to the directions [101], [010], [10 $\overline{1}]$ of the $\beta_{1}$ cubic phase. According to the Neumann principle and the symmetry relationship between the $\beta_{1}$ phase and the $r_{1}{ }^{\prime}$ phase, the strain states caused by a martensitic phase transformation can be calculated. There are only 4 nonzero components of strain, i.e. $\varepsilon_{11}=\varepsilon_{33}, \varepsilon_{22}$ and $\varepsilon_{13}$, and six effective strain states $X\left(S_{k}\right)(k=1-6)$.

Using Aizu's definition [30] for the spontaneous strain tensors,

$$
\mathrm{P}\left(\mathrm{S}_{\mathrm{i}}\right)=\mathrm{X}\left(\mathrm{S}_{\mathrm{i}}\right)-\frac{1}{6} \sum_{\mathrm{k}=1}^{6} \mathrm{X}\left(\mathrm{S}_{\mathrm{k}}\right)
$$

where $P\left(S_{i}\right)$ (i=1-6) denote six effective spontaneous strain states, the spontaneous strain tensors can be calculated, from which the spontaneous shear strain for martensitic transformation should be $\varepsilon_{i j}^{(s)}=2 \varepsilon_{13}$.

In the principal axes coordinate system of the $r_{1}{ }^{\prime}$ orthorhombic phase, we can obtain the strains due to martensitic phase transformation based on the results of $x$-ray diffraction experiments.

$$
\begin{aligned}
& \varepsilon_{11}^{\prime}=\left(a-\frac{\sqrt{2}}{2} a_{0}\right) / \frac{\sqrt{2}}{2} a_{0}=0.061, \quad \varepsilon_{22}{ }^{\prime}=\left(b-a_{0}\right) / a_{0}=-0.082 \\
& \varepsilon_{33}^{\prime}=\left(C-\frac{\sqrt{2}}{2} a_{0}\right) / \frac{\sqrt{2}}{2} a_{0}=0.022, \quad \varepsilon_{i j}^{\prime}(i \neq j)=0
\end{aligned}
$$

Because the principal axes in $r_{1}^{\prime}$ phase are parallel to the directions [101],[010], [10ī] of $\beta_{1}$ cubic phase respectively, the spontaneous shear strain in the $\beta_{1}$ cubic phase coordinate system is

$$
\varepsilon_{i j}^{(s)}=2 \varepsilon_{13}=2 \sum_{i, j=1}^{3} a_{1 \mathrm{i}} a_{3 \mathrm{j}} \varepsilon_{i j}{ }^{\prime}=0.0388
$$

where $a_{11}=a_{31}=a_{33}=\sqrt{2} / 2, a_{13}=-\sqrt{2} / 2, a_{12}=a_{32}=0$. Using the values of $A / k$ and $B$ given under Fig. 9, we obtain

$k=1.6 \times 10^{15} \mathrm{~N} / \mathrm{m}^{3}, \mathrm{k}_{0}=1.54 \times 10^{15} \mathrm{~N} / \mathrm{m}^{3}$ and $\Gamma=11.2 \times 10^{11} \exp [-130 /(363-\mathrm{T})] \mathrm{Kg} / \mathrm{m}^{2} \mathrm{~s}$.

\section{4 $P_{3}$ Peak and Freezing Effect (or Glass Transition) of Domain Walls}

The criterion of a freezing effect is the Vogel-Fulcher relation, $\tau=\tau_{0} \exp \left[\mathrm{E} /\left(\mathrm{T}-\mathrm{T}_{\mathrm{f}}\right)\right]$. Taking the data of $\varepsilon^{\prime}$ and $\varepsilon$ " of the $P_{3}$ peak for TGS (Fig. 3), the V-F plot and Arrhenius plot is shown in Fig. 10. It indeed obey the V-F relation, the same as for KDP (Figure omitted)..

For $\mathrm{Cu}-\mathrm{Al}-\mathrm{Zn}-\mathrm{Ni}$ which was heated at $830^{\circ} \mathrm{C}$ for $10 \mathrm{~min}$ and quenched in water, $\mathrm{Q}^{-1}$ and $\Delta \mathrm{J} / \mathrm{J}$ were measured at $500 \mathrm{~Hz}$ (Fig.11). $\Delta \mathrm{J} / \mathrm{J}$, corresponding to $\varepsilon^{\prime}$, manifests a large kink near $P_{3}$. That means the modulus $M$ shows a hardening process near $P_{3}$, imply the freezing of DWs. Tests of the V-F relation are in progress. 
Three mechanisms have already been proposed to explain the freezing phenomenon. The first Bornavel's[14], is based on quasidislocations of edge type that are known to exist in the DW. He suggests that the critical shear stress to move the quasidislocations depends strongly on temperature. The second, proposed by Fedosov and Sidorkin [15] gives two possible configurations of the DW, $T_{f}$ being the temperature of transition from one to the other. The structure of a $D W$ at $T<T_{f}$ is the same as paraelectric phase, i.e. $P_{B}=0$. The third, proposed by Kuramoto[16] is that the dipole reversal in the DW has a certain size of the cooperative region (cluster), the restriction for the dipole reversal becomes rigid as the spontaneous polarization reaches its saturated value, leading to the freezing of DWs. None of these three has been brought to satisfactory explanation. As Kubinec put it in 1995 [31], "although the domain freezing phenomenon has been known for a long time and was intensively studied in recent years, the problem has not been solved yet".

A new model is needed that must take account of: (1) $T_{f}$ increases with increasing defect density on irradiation [17], (2) $T_{f}$ increases with decreasing thickness $t$ of sample [22], i.e. with the increasing of the density of DWs $N$, due to $N \propto t^{-1 / 2}$ [32]. Therefore the new model must involve not only pinning of defects but also interactions between DWs. Inspired by the model of the collectively-pinned flux glass [33] we propose a model of collectively-pinned domain wall glass. At low temperature, there exist the collective-pinning to DWs between random distribution defects, i.e. the pinning of defects in a certain spatial range is correlative; at the same time, due to the interaction between DWs, an effective pinning region $\Delta S$ forms, i.e. the pinning in $\Delta S$ is correlative or a local order forms. The collective pinning energy $U_{C P}$ is much larger than the individual pinning energy $U_{I P}$, leading to the freezing of $D W s$ or a glass transition at $T_{f}$. At the temperature much higher than $T_{f}$, the individual pinning becomes more and more and then the thermal activated Arrhenius mechanism may contribute to the relaxation.

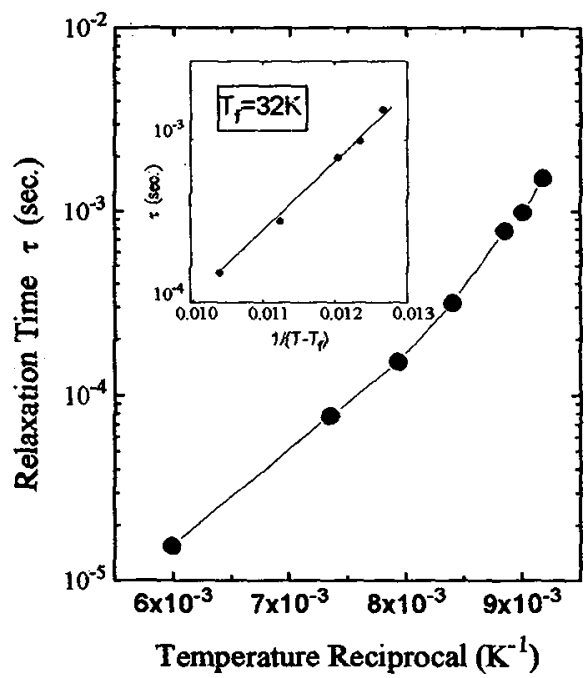

Fig. 10. $\tau$ vs $1 / T$ and $\tau$ vs $1 /\left(T-T_{f}\right.$ ) (inset) for $P_{3}$ of TGS, data taken from Fig.3.

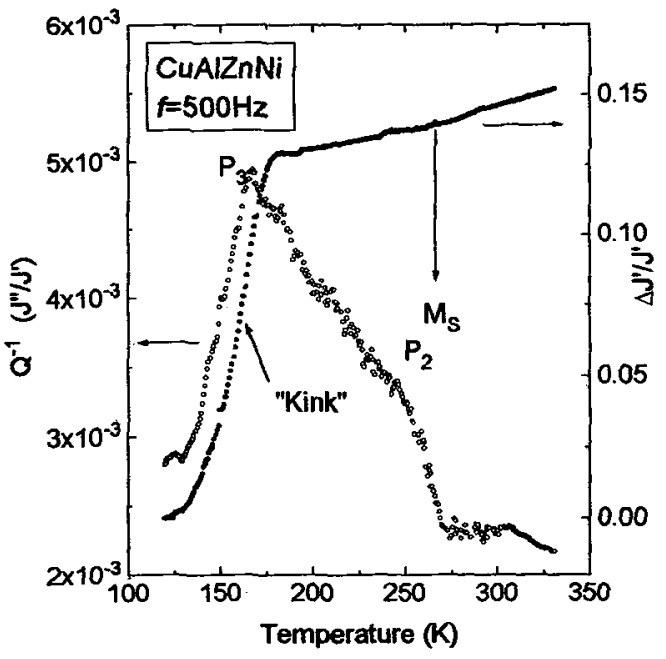

Fig. 11. $\mathrm{Q}^{-1}$ and $\Delta \mathrm{J}^{\prime} / \mathrm{J}^{\prime}$ of $\mathrm{CuAlZnNi}$ as functions of $T$ at $f=500 \mathrm{~Hz}$. 


\section{REFERENCES}

[1] Wang Y.N., Yang Z.J., Zhu H., Ma J.C., Journal of Nanjing University 7 (1963) 1 Wang Yening, Chen Xiaohua and Shen Huimin, Recent Studies on Internal Friction Associated with Diffusionless Phase Transitions and Domain Walls, (Review article), Chin. J. Met. Sci. Technol. 7 (1991) 157

[2] Ma Y.L. and Kê T.S., Acta Phys. Sinica 20 (1964) 72

[3] Christian J.W., J. Inst. Metals. 93 (1965) 546

[4] Postnikov V.S., Gridnev, S.A. NUOVO CMMENTO, 33 (1976) 324

[5] Dejonghe W., Debatist R. and Delaey L., Scripta Metall. 10 (1976) 1125

[6] Mercier O. and Melton K.N., Acta Met. 27 (1979) 1467

[7] Yang Z.J., Zou Y.F., Zhang Z.F. and Wang Y.N., Acta Metall. Sinica 18 (1982) 21

[8] Snead CL, Jr. and Welck D, J de Phys., 46 (1985) C10-589

[9] Wang Y.N., Sun W.Y. and Shen H.M., Phys. Stat. Sol. 102 (1987) 721

[10] Huang Y.N., Wang Y.N. and Shen H.M., Phys. Rev. B 46 (1992) 3290

[11] Wang Y.N., Huang Y.N., Shen H.M. and Zhang Z.F., Studies on Dynamics of Ferroelastic Domain Walls, ISSMM94 Beijing, Sept. 1994, (Chu Y.Y., Tu, H.L. Eds. (Inter. Acad. Publishers, China Building Industry Press)

[12] Shen H.M., Zhang Z.F., Huang Y.N., Yang Z., Wang X.M., Wang Y.N., another report on ICIFUAS-11, accepted

[13] Barkla H.M. and Finlayson D.M., Phil Mag., 44 (1953) 109

[14] Bornarel J., J. Appl. Phys. 43 (1972) 3

[15] Fedosov V.N. and Sidorki A.S., Sov. Phys. Solid 19 (1977) 1359

[16] Kuramoto K., J. Phys. Soc. Jpn., 56 (1987) 1859

[17] Kamysheva L.N. and Drozhdin S.N., Ferroelectrics 71 (1987) 281

[18] Bornarel J., Ferroelectrics 71 (1987) 255

[19] Nakamura E. and Kuramoto K., J. Phys. Soc. Jpn, 51 (1988) 2182

[20] Hayashi K., Deguchi K. and Nakamura E., J. Phys. Soc. Jpn, 51 (1988) 3594

[21] Nakamura E., Kuramoto K., Deguchi K. and Hayashi K., Ferroelectrics, 98 (1989) 51

[22] Bornarel J. and Torche B., Ferroelectrics 135 (1992) 273

[23] Nakamura E., Ferroelectrics, 135 (1992) 237

[24] Vogel, H.Z., Phys. 22 (1921) 645, Fulcher, G.S., J Am. Ceram. Soc. 8 (1925) 339

[25] Worrel, F., Phys. Rev., 72 (1947) 533

[26] Hasiguti, R and Iwasaki, K., J. Appl. Phys. 39 (1968) 3182

Zhu, J.S., Schaller, R. and Benoit, W., Phys. Lett. A 30 (1989) 177

[27] Van Humbeek, J and Delaey, L., J de Phys., 44 (1983) C9-217

[28] Comb, Andrew J. and Yip,Sidney, Phys. Rev. B 11 (1975) 3535

[29] Otsuka K. and Shimizu K., Trans. Japan Inst. Metals 15 (1974) 103

[30] Aizu, K., J. Phys. Soc. Japan 28 (1970) 706

[31] Kubinee, P., Fall, M., Tuith, A., Kabelka, H. and Filipic, C. , J. Phys.: Condensed Matter, 7(1995) 2205

[32] Abe, K., J Phys. Soc. Jpn., 56 (1987) 757

[33] Blatt, G., Feigelman, M.V., Larkin, A.I. and Vinokur, V.M. , Rev. Mod. Phys. 66 (1994) 1125 